Objectives Objective of this study was to present characteristics of Ankylosing spondilitis (AS), not initiated as genuine (i.e. initiating as a reactive arthritis-ReA).

Methods The study is a retrospective 20-year analysis of 144 patients treated for ReA.

Results

- Spondylitis occurred after either urinary or intestinal infection in $87 \%$; in $53 \%$ - following mono- or oligoarthritis.

- Syndesmophytes of one or more segments were massive, nonmarginal; sacroiliitis-asymmetrical.

- After the period of 10,6 years, in $25 \%$ of diseased, the total spinal column was involved by AS type, with symmetrical sacroiliitis.

- Some discs presented with calcification resulting from discitis.

- Some i.v. spaces were reduced including some vertebral bodies which underwent a cuneiform transformation.

- Postural transformation was less frequent, lumbar lordosis was recorded in $83 \%$ with lower frequency of $\mathrm{TH}$ kyphosis than in AS.

- There were cases of interspinal arthrosis and other secondary degenerative transformations.

- Neurological and/or motorial deficit was recorded in $85 \%$ (damage of sensibility, tendon reflexes or motoricity).

- Function of the spinal column was preserved for the period of 10,5 years on average if the process was of segment character, which referred also to the respiratory function in which the abdominal type of breathing was predominant after 15,5 years.

Conclusion The presented differences occur for slow process of development of $\mathrm{Sp}$ in ReA, because of the involvement of either one or a small number of vertebral units of the spinal column and the presence of discitis, whereas in AS, the course of ossification of the fibres of annulus fibrosus is faster than the destruction of the discus, inner fibres of annulus fibrosus and nucleus pulposus being preserved, in this way the i.v. spaces remain unreduced, not allowing neither discovertebral conflict nor the resulting neurological damage.

\section{SAT0008 BONE MASS EVALUATION USING QUANTITATIVE COMPUTED TOMOGRAPHY IN ANKYLOSING SPONDYLITIS}

${ }^{1}$ A El Maghraoui, ${ }^{2} S$ Chaouir, ${ }^{1}$ A Bezza, ${ }^{1} \mathrm{~F}$ Tabache, 'D Ghafir, ${ }^{1} \mathrm{~V}$ Ohayon, ${ }^{1} \mathrm{Ml}$ Archane. ${ }^{1}$ Internal Medicine; ${ }^{2}$ Radiology, Military Hospital Mohamed V, Rabat, Morocco

\subsection{6/annrheumdis-2001.360}

Background Osteoporosis (OP) is now a well recognised feature of ankylosing spondylitis (AS). Dual energy x-ray absorptiometry, which is the most routinely used method to assess OP, fails to demonstrate spine OP in patients with late stage disease (syndesmophytes and facet joints ankylosis). Therefore, quantitative computed tomography (QCT) is the only method that can evaluate correctly the spinal OP in patients with advanced spinal changes.

Objectives To study OP prevalence in AS using QCT and relationship between OP and AS symptomatic and structural severity.

Methods 27 patients with AS were enrolled prospectively: 24 men $(88.8 \%)$ and 3 women with mean age of $37.7 \pm 9.2$ years [17-66] and mean disease duration of $7.6 \pm 4.7$ years [0.4-19]. The patients were studied clinically, radiologically and by QCT.

Results OP at the lumbar spine as defined by $\mathrm{Z}$ score $<-1$ was observed in 11 patients (40.7\%). Osteoporotic patients were older than normals (42.3 yrs (9.8) vs $34.6(7.6) ; \mathrm{p}=0.03)$ and had more severe disease as showed the significant statistical differences in symptomatic and structural parameters (chest expansion, BASMI, BASRI, and syndesmophyte score). There was a negative significant statistical correlation between $\mathrm{Z}$ score and Schöber index, chest expansion, BASMI and radiological indexes (syndesmophytes score, BASRI).

Conclusion

- OP is frequent in AS.

- Patients with AS are more susceptible to develop OP when they have active and severe disease.

\section{SAT0009 CERVICAL SPINE INVOLVEMENT IN ANKYLOSING SPONDYLITIS}

A El Maghraoui, R Bensabbah, R Bahiri, A Bezza, N Guedira, N Hajjaj-Hassouni. Internal Medicine Department, Military Hospital Mohamed V, Rabat, Morocco

10.1136/annrheumdis-2001.361

Background

Objectives To study cervical spine involvement in ankylosing spondylitis (AS) and evaluate correlations with disease symptomatic and structural severity.

Methods Prospective evaluation of AS during one year. Clinical, biological, and radiological data were collected. The risk of CS involvement was estimated using Kaplan-Maier?s method.

Results 61 patients were enrolled: 38 males (62.2\%) and 23 females of mean age 35.1 yrs (11) [range 17-66]. The mean disease duration was 10.6 yrs (7) [0.5-30]. Forty three patients $(70.4 \%)$ had history of neck pain. Radiological involvement was present in 33 cases (54\%). The concordance between clinical and radiological presentation was statistically significant $(\mathrm{k}=$ $0.49 ; \mathrm{p}<1-6)$. The risk of the cervical spine involvement with regard to disease duration showed that $19.6 \%$ of patients had radiological involvement after 5 years of disease duration, $29.9 \%$ after 10 years, $45.1 \%$ after 15 years and $70.0 \%$ after 20 years. Comparison between patients with and without cervical spine radiological involvement showed no difference in age of onset or sex. There was statistical difference in symptomatic severity parameters (Schöber, chest expansion, BASMI, BASFI, BASDAI, BASG) and structural severity parameters (lumbar syndesmophytes score, BASRI). There was a significant correlation between cervical spine radiological scores (facet joint score and BASRI) and age, disease duration, and symptomatic severity indexes (chest expansion, Schober, BASMI, BASFI) and disease activity index (BASDAI).

Conclusion Cervical spine involvement increases with age and disease duration in AS. Its severity is correlated to symptomatic and structural severity indexes of the disease.

\section{SAT0010 THORACIC HIGH RESOLUTION COMPUTED TOMOGRAPHY IN PATIENTS WITH ANKYLOSING SPONDYLITIS AND WITHOUT RESPIRATORY SYMPTOMS}

${ }^{1} \mathrm{~A}$ El Maghraoui, ${ }^{2} \mathrm{~S}$ Chaouir, ${ }^{1} \mathrm{~F}$ Tabache, ${ }^{1} \mathrm{~A}$ Bezza, ${ }^{1} \mathrm{D}$ Ghafir, ${ }^{1} \mathrm{~V}$ Ohayon, ${ }^{1} \mathrm{Ml}$ Archane. ${ }^{1}$ Internal Medicine Department; ${ }^{2}$ Radiology Department, Military Hospital Mohamed V, Rabat, Morocco

10.1136/annrheumdis-2001.362

Background

Objectives To identify the spectrum of abnormalities seen on thoracic High Resolution Computed Tomography (HRCT) in 